Ciência Florestal, Santa Maria, v. 23, n. 3, p. 439-448, jul.-set., 2013

ISSN 0103-9954

\title{
COMPETITIVIDADE DO BRASIL E CANADÁ NO MERCADO DE MADEIRA SERRADA DE CONÍFERAS
}

\author{
COMPETITIVENESS OF BRASILIAN AND CANADIAN SOFTWOOD LUMBER MARKET
}

Alexandre Nascimento de Almeida ${ }^{1}$ João Carlos Garzel Leodoro da Silva ${ }^{2}$ Humberto Angelo ${ }^{3}$

\section{RESUMO}

A sobrevivência das empresas em um cenário de globalização acelerada e concorrência crescente depende dos seus graus de competitividade. Para a conquista de competitividade, não basta apenas fazer as coisas certas, é preciso fazer melhor que os concorrentes, neste aspecto, a busca pela comparação aos melhores padrões mundiais torna-se fundamental para o aprimoramento de práticas industriais e comerciais. Em relação à produção de madeira serrada, o Canadá é um grande exemplo mundial e, portanto, bom parâmetro para comparação. O objetivo desse trabalho foi o de comparar e explicar a competitividade entre o Brasil e Canadá para o mercado de madeira serrada de coníferas. Para tanto, utilizaram-se as metodologias: Índice de Vantagem Comparativa Revelada e Análise de Regressão para comparação e explicação da competitividade, respectivamente. Os resultados indicaram que, além do Canadá ser mais competitivo que o Brasil, a competitividade brasileira no mercado de madeira serrada de coníferas é mais dependente da taxa de câmbio.

Palavras-chave: competitividade; IVCR; madeira serrada; Canadá.

\begin{abstract}
The survival of business in a scenario of accelerated globalization and increasing competition depends on its degree of competitiveness of the business. In this aspect, the comparison among the world's best standards is fundamental for the improvement of industrial and commercial practices. Canada is an excellent example and parameter to use as a comparison in the Softwood Lumber industry with Brazil's industry. The aim of this paper was to compare and to explain the competitive Softwood Lumber markets between Brazil and Canada. For this purpose, the methodologies used were: Index of Revealed Comparative Advantage and Regression Analysis for comparison and explanation of competitiveness, respectively. The results indicated that, besides Canada being more competitive than Brazil, the Brazilian competitiveness in the market for softwood lumber is more dependent on the exchange rate.
\end{abstract}

Keywords: competitiveness; IRCA; sawnwood; Canada.

\section{INTRODUÇÃO}

A principal função dos estudos de competitividade é permitir uma comparação entre os melhores padrões mundiais de produção, objetivando identificar vantagens e desvantagens competitivas, contribuindo para o aprimoramento de medidas políticas e práticas produtivas.

Em um cenário mundial de globalização, o crescente liberalismo comercial tem acirrado a concorrência, tornando a busca pela competitividade ainda mais importante para a sobrevivência das empresas. Nesse contexto, para Pinto (2004), a globalização da economia, fenômeno que derruba fronteiras e define uma nova ordem para a gestão dos negócios em todos os segmentos, impõe ao agronegócio brasileiro uma revisão completa de suas práticas e conceitos.

1 Engenheiro Florestal, Dr., Professor dos cursos de Gestão Ambiental e do Agronegócio, Universidade de Brasília, Faculdade de Planaltina, Área Universitária n. 1, Vila Nossa Senhora de Fátima, CEP 73300-00, Planaltina (DF). alexalmeida@unb.br

2 Engenheiro Florestal, Dr., Professor do Departamento de Economia Rural e Extensão, Universidade Federal do Paraná, Av. Lothário Meissner, 900, Jardim Botânico, Campus III, CEP 80210-170, Curitiba (PR). garzel@ufpr.br

3 Engenheiro Florestal, Dr., Professor do Departamento de Engenharia Florestal, Universidade de Brasília, Faculdade de Tecnologia, Caixa Postal 04357, Asa Norte, CEP 70919-970, Brasília (DF). humb@unb.br

Recebido para publicação em 19/07/2011 e aceito em 8/02/2012 
No segmento de madeira serrada, o Canadá é um bom exemplo comparativo, pois está entre os grandes players mundiais, podendo ser considerado como um ponto de referência e um padrão mundial a ser alcançado. Segundo FAO (2010), nas últimas décadas, o Canadá tem sido o maior exportador mundial de madeira serrada.

Uma maneira de comparar a competitividade entre dois segmentos, indústrias ou países é por meio do Índice de Vantagens Comparativas IVCR. O IVCR é fundamentado na importância de um segmento nas exportações totais de um país, ou seja, a obtenção de resultados expressivos de um segmento na pauta de exportações de um país, comparativamente aos seus concorrentes, revela vantagens comparativas desse segmento perante o mundo.

De acordo com Nonnenberg (1991), com o incremento do comércio internacional, a necessidade de conhecer os segmentos em que o Brasil apresenta vantagens comparativas é fundamental. $\mathrm{Na}$ verdade, ainda mais importante é determinar os fatores nos quais estão baseadas essas vantagens.

O objetivo desse estudo é comparar a competitividade entre o Brasil e Canadá no mercado de madeira serrada de coníferas, por meio do IVCR, bem como explicar os fatores que sustentaram essa competitividade, via análise de regressão. Por um lado, o Canadá apresenta melhores condições de infraestrutura e tecnologia, por outro, a competitividade do Brasil é favorecida pela maior produtividade das florestas e por um mercado interno em crescimento, elevando a importância do estudo diante da incerteza dos resultados.

\section{MATERIAL E MÉTODOS}

\section{Referencial teórico}

Durante os séculos dezessete e dezoito, um grupo de homens (comerciantes, banqueiros, funcionários públicos e até mesmo filósofos) escreveram ensaios e panfletos sobre o comércio internacional, em que defendiam uma filosofia econômica conhecida como mercantilismo, estes foram os primeiros a elaborarem teorias sobre o comércio internacional. Os mercantilistas acreditavam que a maneira de uma nação tornar-se rica e poderosa era exportar mais do que importar, pregando um nacionalismo econômico e um idealismo protecionista (SALVATORE, 1998).

Em reação às ideias nacionalistas dos mer- cantilistas, surgiram as ideias liberais de Adam Smith e David Ricardo sobre comércio internacional. Refutando qualquer forma de protecionismo, Adam Smith e David Ricardo acreditavam que o comércio é mutuamente benéfico para os envolvidos, pois, dadas as diferenças dos países, o melhor resultado seria se os países exportassem as mercadorias as quais possuíssem vantagens competitivas e importassem aquelas em que fossem menos eficientes (KRUGMAN e OBSTFELD, 2004).

De acordo com Adam Smith, o comércio entre duas nações baseia-se nas vantagens absolutas, ou seja, o comércio será mutuamente benéfico se os países se especializarem e comercializarem os bens em que possuem vantagens absolutas (KENEN, 1998).

David Ricardo completou o pensamento de Adam Smith por meio da lei das vantagens comparativas. Segundo David Ricardo, mesmo que uma nação não possua nenhuma vantagem absoluta, existe, ainda, uma base para um comércio mutuamente benéfico. A primeira nação deveria especializar-se na produção e exportação da commodity na qual a sua desvantagem absoluta seja menor (esta é a commodity de sua vantagem comparativa) e importar a commodity na qual a sua desvantagem absoluta seja maior (SALVATORE, 1998).

Um dos primeiros a validar empiricamente a lei das vantagens comparativas foi Béla Balassa e, a partir de suas evidências favoráveis, propôs o Índice de Vantagens Comparativas - IVCR para medir a competitividade (SALVATORE, 1998; BALASSA, 1965).

O IVCR é fundamentado na teoria de que o comércio mundial entre os países se ajusta conforme as suas vantagens comparativas. $\mathrm{O}$ índice assume que, resultados expressivos no comércio mundial revelam as vantagens comparativas das nações em determinados bens, partindo do pressuposto de que as nações naturalmente direcionam suas exportações para os produtos que são mais competitivos. Assim, quanto mais importante for a participação de um segmento nas exportações totais de um país, mais vantagens competitivas o país possui nesse determinado segmento.

No setor florestal brasileiro, o estudo da competitividade por meio do IVCR ainda é pouco difundido à exceção do trabalho de Carvalho et al. (2009). Porém, na agricultura são encontrados diversos trabalhos, como exemplos: Maia et al. (2008); Ropke e Palmeira (2006); Figueiredo e Santos (2005); entre outros. 
Destaca-se um conjunto de trabalhos que trataram a competitividade no setor florestal, porém, por meio de outro indicador, o Constant Market Share - CMS: Noce et al. (2008) para o aglomerado; Noce et al. (2003) para madeira serrada de coníferas e folhosas; Valverde et al. (2006) para celulose. O CMS e o IVCR se assemelham pelo fato de ambos os indicadores serem construídos com dados de exportação, porém, o CMS mede a competitividade por meio da evolução do market share (fatia de mercado) de um país, partindo do pressuposto de que países competitivos são aqueles que conseguem conquistar, ou não perder mercado externo, em uma proporção acima da média mundial, não levando em consideração o desempenho de outros segmentos da economia como o IVCR.

O IVCR, embora prático para mensurar a competitividade, possui como principal limitação o fato de não explicar a mesma (PINHEIRO e HORTA, 1992). Porém, uma forma de mitigar essa limitação é estimá-lo em um período histórico e explicá-lo via análise de regressão (HOLANDA, 2002 e MAIA et al., 2008).

A explicação completa da competitividade demanda análise de algumas variáveis, quais sejam, conforme Coutinho e Ferraz (1994):

- A capacitação tecnológica e produtiva;

- A qualidade e produtividade dos recursos humanos e insumos para produção;

- O conhecimento de mercado e a capacidade de se adequar às suas especificidades;

- A qualidade e a amplitude de serviços pós-vendas;

- As relações privilegiadas com usuários e fornecedores;

- Custos de comercialização;

- Grau de concentração da indústria que a empresa atua;

- Escala de produção;

- Taxa de câmbio, oferta de crédito e taxas de juros;

- Políticas tributárias e tarifárias;

- Políticas de proteção à propriedade industrial, de preservação ambiental, de defesa da concorrência e proteção ao consumidor;

- Disponibilidade, qualidade e custo de energia, transportes, telecomunicações e serviços tecnológicos;

- Grau de exigência dos consumidores domésticos;

- Acordos internacionais.

\section{Referencial analítico}

\section{Índice de vantagem comparativa revelada}

O IVCR pode ser definido conforme a equação [1].

$$
\mathrm{IVCR}=(\mathrm{EMS} / \mathrm{ET}) \div(\mathrm{EMSM} / \mathrm{EMT})
$$

EMS - valor real das exportações de madeira serrada de coníferas dos países em análise (Brasil e Canadá)

ET - valor real das exportações totais brasileiras e canadenses

EMSM - valor real das exportações de madeira serrada de coníferas do mundo mundiais

ETM - valor real das exportações totais

Se IVCR é maior do que 1 , o país em análise é considerado competitivo nas exportações de madeira serrada de coníferas. Se IVCR é igual a 1 , o país desfruta da mesma competitividade da média vigente no mercado internacional. Finalmente, se IVCR varia entre 0 e 1 , o país é definido como tendo desvantagem comparativa do produto analisado.

\section{Análise de regressão}

Conforme Coutinho e Ferraz (1994), o leque de possíveis variáveis explicativas da competitividade é enorme e, naturalmente, a ideia da construção de um modelo de regressão não é analisar o efeito de todas as variáveis. Neste caso, o modelo se tornaria extremamente complexo e de pouca praticidade. Já, Almeida et al. (2009a) e o Instituto Brasileiro de Geografia e Estatística - IBGE (2010) consideraram as variáveis explicativas: taxa de câmbio e custos de produção com matéria-prima e mão de obra como determinantes da competitividade do Brasil e Canadá no mercado de madeira serrada de coníferas para o período de 1994 a 2008.

Almeida et al. (2009a) destacaram a dependência histórica do câmbio para a competitividade do segmento de madeira serrada de coníferas no Brasil. Já o IBGE (2010), apontou que a participação média conjunta dos custos com matéria-prima e mão de obra representaram, aproximadamente, $90 \%$ dos custos totais operacionais das serrarias no Brasil. Para o Canadá essa participação contabilizou $97 \%$, conforme o departamento de Estatística Industrial do Canadá - CIS (2010). 
Optou-se pela taxa de câmbio real em relação ao dólar devido à importância dos EUA no comércio internacional de madeira serrada do Brasil e Canadá. Historicamente, mais da metade da produção de madeira serrada de coníferas do Brasil e cerca de $2 / 3$ da produção canadense têm sido exportadas para os EUA (UnCOMTRADE, 2010).

Definida as variáveis, especificou-se o modelo explicativo do IVCR calculado para o Brasil e Canadá, na sua forma logarítmica conforme a equação [2].

$$
\begin{aligned}
\operatorname{lnIVCR}_{\mathrm{t}}=\alpha_{1}+\alpha_{2} \ln \mathrm{C}_{\mathrm{t}}+\alpha_{3} \operatorname{lnMP} \mathrm{P}_{\mathrm{t}}+\alpha_{4} \ln \mathrm{S}_{\mathrm{t}}+\varepsilon_{\mathrm{t}} \text { [2] } \\
\text { C }- \text { Taxa de Câmbio Real } \\
\text { MP }- \text { Preço Real da Madeira em Tora para }
\end{aligned}
$$
Serraria

S - Valor Real dos Salários para Serraria

$\varepsilon$ - Termo de erro do modelo

Depois de determinadas as variáveis, o próximo passo inerente à construção de um modelo de regressão é identificar quais são as hipóteses esperadas ou, em outras palavras, identificar a direção do efeito das variáveis conforme a teoria existente (KOUTSOYIANNIS, 1978).

A expectativa é para um efeito positivo para a taxa de câmbio $\left(\alpha_{2}>0\right)$ e negativo para os custos de produção referentes à mão de obra e matéria-prima $\left(\alpha_{3}\right.$ e $\left.\alpha_{4}<0\right)$. Uma apreciação cambial eleva o preço dos bens internos em comparação com os externos, acarretando uma perda de competitividade. Já um aumento dos custos de produção, reduz a lucratividade $\mathrm{e}$, consequentemente, leva à perda de competitividade.

A estimativa do modelo considerou o método dos Mínimos Quadrados Ordinários - MQO, e a forma funcional empregada foi a logarítmica, devido à possibilidade de obtenção das elasticidades diretamente. Todas as hipóteses foram avaliadas por meio do teste $t$ unicaudal, admitindo valores significativos a um nível de até $10 \%$.

Em um modelo de regressão linear pelo método MQO, a validade da interpretação dos parâmetros estimados depende de uma série de hipóteses referentes às variáveis explicativas e ao termo de erro. Segundo Gujarati (2000), pode-se resumir em 11 hipóteses básicas para a obtenção de estimativas desejáveis em um modelo de regressão:

$1^{\circ}$ Linearidade nos parâmetros;

2o Os valores das variáveis explicativas são fixados em amostragem repetida;

$3^{\circ}$ Valor médio zero do termo de erro;
4ํAs variâncias do termo de erro são idênticas para todas as observações;

5을 Ausência de autocorrelação entre os termos de erro;

6o Covariância zero entre os termos de erro e as variáveis explicativas;

7ํNúmero de observações deve ser maior que o de parâmetros a serem estimados;

$8^{\text {o }}$ Variabilidade nos valores das variáveis explicativas;

$9^{\circ} \mathrm{O}$ modelo de regressão está corretamente especificado;

$10^{\circ}$ Não há relações lineares perfeitas entre as variáveis explicativas; e

$11^{\circ} \mathrm{O}$ termo de erro se distribui normalmente.

A análise econométrica foi concentrada nas hipóteses 4, 5, 7, 8, 9 e 10. Com isto, a hipótese 1 assume que o fenômeno em estudo é linear nos parâmetros, porém, independente da confirmação dessa lineariedade, foi admitido uma aproximação linear, tendo em vista o ganho de simplicidade do modelo. Já as hipóteses 2 e 6 , não são passíveis de serem cumpridas devido à falta de controle sobre os dados, pois, os mesmos são secundários, ou seja, dados coletados por outros.

Conforme Gujarati (2000), a importância da hipótese 3 é para uma estimativa não viesada do termo de intercepto. Em virtude do termo de intercepto não ser relevante para a análise realizada, foi desnecessária uma análise minuciosa dessa hipótese.

As hipóteses 4,5 e 9 , referentes à ausência de problemas de heteroscedasticidade, autocorrelação e especificação, foram analisadas pelos testes formais propostos por: White (1980) para heteroscedasticidade e especificação, e Durbin e Watson (1951) para autocorrelação.

As hipóteses 7 e 8 , número de observações maior que o número de parâmetros estimados e variabilidade nos valores das variáveis explicativas, foram atendidas. Porém, um problema relacionado à hipótese $7 \mathrm{e}$, normalmente, pouco abordado é a questão da micronumerosidade ou pequenez do tamanho da amostra. A avaliação desse problema foi a partir das sugestões realizadas por Hair et al. (2005). Segundo os autores, a proporção mínima entre as observações e variáveis explicativas é de 5 para 1 e o nível desejado está entre 15 e 20 observações para cada variável explicativa.

As hipóteses 10 e 11, multicolineariedade e normalidade dos resíduos, foram analisadas pelos valores do Fator de Inflação de Variância - FIV e do teste de normalidade de Shapiro-Wilk. Como regra 
prática, o valor adotado para avaliar o FIV foi 10 , assim, a obtenção de valores superiores a esta base são indicativos de problemas de multicolineariedade (GUJARATI, 2000).

\section{Banco de dados}

Os dados de exportações utilizados para construção do IVCR foram coletados junto ao UnCOMTRADE (2010). As paridades entre o Real (R\$) e o Dólar canadense (C\$) com o Dólar dos EUA (US\$) podem ser obtidas por meio do banco de dados do Instituto de Pesquisa Econômica Aplicada - IPEA (2010). O valor dos salários e o custo da madeira em tora para serraria podem ser coletados junto ao IBGE (2010) para o Brasil e CIS (2010) e BC (2010) para o Canadá. Na correção de todas as séries, consideraram-se os Índices de Preço ao Consumidor dos respectivos países, para o Brasil, utilizou-se o Índice de Preço ao Consumidor Amplo - IPCA, podendo ser coletadas junto ao IPEA(2010).

\section{RESULTADOS E DISCUSSÃO}

\section{Comparações entre a competitividade do Brasil e Canadá}

Embora as vantagens competitivas do Canadá venham reduzindo gradativamente, conforme os valores de IVCR calculados (Figura 1), a competitividade canadense ainda é bem superior a do Brasil no mercado de madeira serrada de coníferas. Diferentemente dos resultados para o Brasil, durante o período analisado de 1994 e 2008, os valores de IVCR para o Canadá foram bem superiores à unidade.

O Brasil registrou ganhos em competitividade entre 1994 e 2002, porém, esses não foram sustentáveis, visto a queda continua do IVCR após 2002, sugerindo que o país está longe de se autoafirmar no mercado de madeira serrada de coníferas e não vem aproveitando a perda de competitividade canadense (Figura 1). Além disso, depois do ano de 2006, o Brasil deixou de ser competitivo perante o mundo. Os melhores resultados para o IVCR brasileiro foram entre 1999 e 2005 e, mesmo assim, apenas pouco acima da unidade.

\section{Explicação da competitividade do Brasil e Canadá}

Os resultados dos modelos explicativos do IVCR para madeira serrada de coníferas, bem como seus indicadores estatísticos, foram de acordo com as equações [3] e [4] para o Brasil e Canadá, respectivamente.

$$
\begin{aligned}
& \operatorname{lnIVCR}_{t}^{\mathrm{B}}=9,47+1,86 \operatorname{lnC}_{\mathrm{t}}-0,87 \operatorname{lnMP}_{\mathrm{t}}-0,79 \operatorname{lnS} \mathrm{S}_{\mathrm{t}} \\
& \text { [3] } \\
& \begin{array}{lllll}
\text { valor } p & 0,03 & 0,01 & 0,06 & 0,09
\end{array} \\
& \text { FIV } \quad 2,59 \quad 4,24 \quad 2,64 \\
& \mathrm{~N}=15 \quad \mathrm{R}_{\text {aj }}^{2}=0,80 \quad \mathrm{~F}=19,34 \quad d=1,60
\end{aligned}
$$

$\operatorname{lnIVCR}_{\mathrm{t}}^{\mathrm{C}}=-9,04+0,40 \operatorname{lnC}_{\mathrm{t}}-0,91 \operatorname{lnMP_{\mathrm {t}}}-0,70 \ln \mathrm{S}_{\mathrm{t}}$ [4]

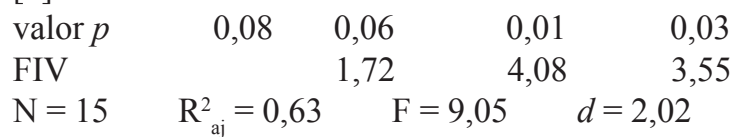

Conforme as equações [3] e [4], todos os coeficientes representativos das variáveis explica-

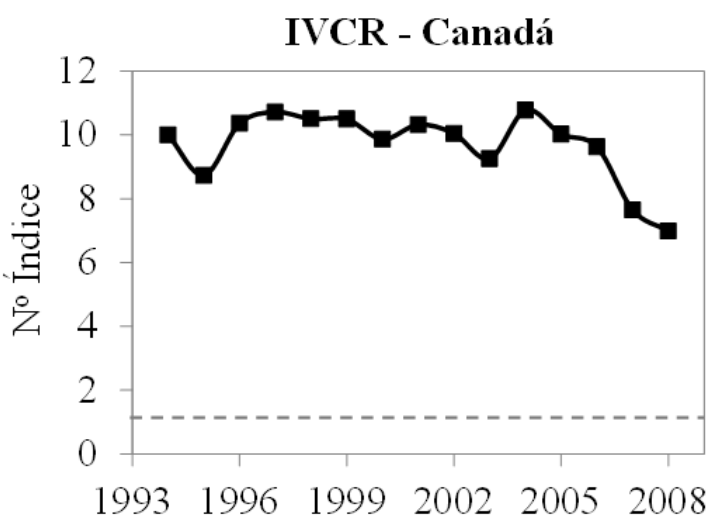

FIGURA 1: Evolução do Índice de Vantagem Comparativa Revelada para o Brasil e Canadá entre o período de 1994 e 2008.

FIGURE 1: Evolution of Revealed Comparative Advantage Index for Brazil and Canada over the period between 1994 and 2008. 
tivas câmbio e custos de matéria-prima e mão de obra obtiveram os sinais esperados e apresentaram-se estatisticamente significativos ao nível de 10\%. O câmbio e custos com matéria-prima para o Brasil e Canadá foram significativos a $1 \%$ e o custo com mão de obra para o Canadá foi significativo a $5 \%$.

Além disso, apenas as três variáveis consideradas explicaram, respectivamente, $80 \%$ e $63 \%$ da evolução da competitividade do Brasil e Canadá, sugerindo a maior dependência brasileira em relação a essas três variáveis do que o segmento canadense. Em outras palavras, o segmento canadense de madeira serrada utiliza outros fatores para definir sua competitividade, podendo, muitos deles, estar ou não sob seu controle.

Por fim, ratificando a relevância das variáveis explicativas, o teste $\mathrm{F}$ atestou que o conjunto das variáveis utilizadas foi estatisticamente significativo ao nível de 1\% para ambos os modelos.

A avaliação econométrica foi satisfatória, não indicando maiores problemas de heteroscedasticidade, autocorrelação, especificação, micronumerosidade, multicolineariedade e normalidade nos modelos estimados.

O teste de White rejeitou problemas de heteroscedasticidade e especificação ao nível de $1 \%$ e a estatística $d$ de Durbin e Watson (1951) rejeitou problemas de autocorrelação ao mesmo nível de significância.

O tamanho da amostra de 15 unidades nas estimativas para o Brasil e Canadá foi de acordo com a proporção mínima sugerida por Hair et al. (2005) de 5 casos para cada variável explicativa, minimizando maiores problemas de micronumerosidade.

As equações [3] e [4] apresentaram valores de FIV inferiores a 10 e o teste de Shapiro-Wilk admitiu um comportamento normal dos resíduos ao nível de $1 \%$, assim, minimizando maiores problemas de multicolineariedade e normalidade dos resíduos.

A discrepância entre os resultados do IVCR para o Brasil e Canadá deve ser minimizada em função do maior equilíbrio entre os setores da economia canadense. Pois, no Brasil, ocorre uma grande discrepância entre a competitividade de matérias-primas e produtos industrializados, o que influencia negativamente os resultados do IVCR para qualquer segmento industrial no Brasil, portanto, demandando cautela na análise dos mesmos.

O comportamento do IVCR brasileiro para madeira serrada de coníferas pode ser claramente dividido entre três períodos: um crescimento até 1999 , seguido por um curto período de oscilação entre
1999 e 2002, para então mergulhar em uma queda até 2008, último ano da análise. Aparentemente, o crescimento nos anos 90 e queda na década seguinte foi decisivamente influenciado pela mudança na política cambial brasileira.

A política cambial vigente no Brasil na década de 90 foi a de um câmbio fixo artificialmente apreciado como âncora de combate à inflação e, a partir de 1999, o país adotou uma política de câmbio flutuante. Embora a política de câmbio flutuante seja muito importante para controlar ataques especulativos externos, até então, o equilíbrio da taxa de câmbio nessa política no Brasil ocorreu à custa de uma forte oscilação do real, dificultando a capacidade de planejamento em longo prazo das empresas. Em se tratando de câmbio, a apreciação do real, bem como a sua constante oscilação, são prejudiciais para a competitividade das empresas.

A evolução da competitividade canadense pode ser dividida em dois momentos. Primeiro, há uma estabilidade até 2006 seguido por uma forte queda até 2008 em função, provavelmente, de reflexos da recente crise mundial originada no mercado da construção civil dos EUA, porém, com o país continuando com valores de IVCR bem acima da unidade e, portanto, altamente competitivo. Embora a bolha na construção civil americana tenha estourado em 2008, esse mercado, que é um grande consumidor de madeira canadense, já vinha mostrando fraqueza desde 2005 (USCB, 2010).

A principal diferença entre os parâmetros estimados para Brasil e Canadá deve-se ao efeito do câmbio. A competitividade do Brasil para o segmento de madeira serrada mostrou-se altamente dependente do câmbio, onde a desvalorização em $1 \%$ do Real leva a um aumento de $1,86 \%$ da competitividade do Brasil. Para o Canadá o efeito do câmbio foi inelástico, sugerindo que uma desvalorização de $1 \%$ no dólar canadense leva a um aumento de apenas $0,4 \%$ da competitividade do país.

Provavelmente, a maior dependência do câmbio no Brasil deva-se à menor capacidade gerencial e financeira das empresas neste país. A maior competitividade do segmento de serrados canadense reflete uma maior lucratividade das suas empresas, sugerindo uma maior resistência a perdas cambiais devido a oscilações de curto prazo e, consequentemente, uma influência inelástica dessa variável. Resultados similares foram encontrados por Almeida et al. (2009a), analisando o efeito do câmbio em dois segmentos com capacidades financeiras distintas, as fábricas de papel e celulose e as serrarias no Brasil. 
Para o Brasil e Canadá, o efeito do custo com matéria-prima foi próximo a uma elasticidade unitária e apresentou coeficientes com magnitudes ligeiramente superiores aos valores alcançadas para os custos com mão de obra, os quais foram inelásticos para ambos os países analisados.

O maior impacto do custo com matéria-prima foi esperado devido ao fato do custo com mão de obra representar uma fatia menor nos custos totais para produção da madeira serrada no Brasil e Canadá. De acordo com o IBGE (2010) e CIS (2010), em média, os custos com matéria-prima, entre 1998 e 2007, representaram, respectivamente, 56 e $79 \%$ dos custos totais para produção de madeira serrada no Brasil e Canadá. Segundo as mesmas fontes e para o mesmo período, os custos com mão de obra responderam por
34 e 18\% dos custos totais para o Brasil e Canadá, respectivamente.

A dependência do câmbio pelo Brasil no mercado de madeira serrada de coníferas é evidente. Conforme a Figura 2, a evolução das séries do câmbio e do IVCR são praticamente idênticas, portanto, altamente correlacionadas. O pico da competitividade no Brasil ocorreu em 2002, um ano antes do melhor momento cambial para as empresas de madeira serrada. Isto se deve, provavelmente, ao forte aumento que o preço da madeira sofreu a partir de 2002, o que contribuiu para descompensar as vantagens cambiais para madeira serrada no ano de 2003. A partir de 2003, o câmbio entrou em uma tendência contrária à competitividade, e o preço da madeira registrou apenas uma pequena queda, não compensando as perdas com o câmbio.
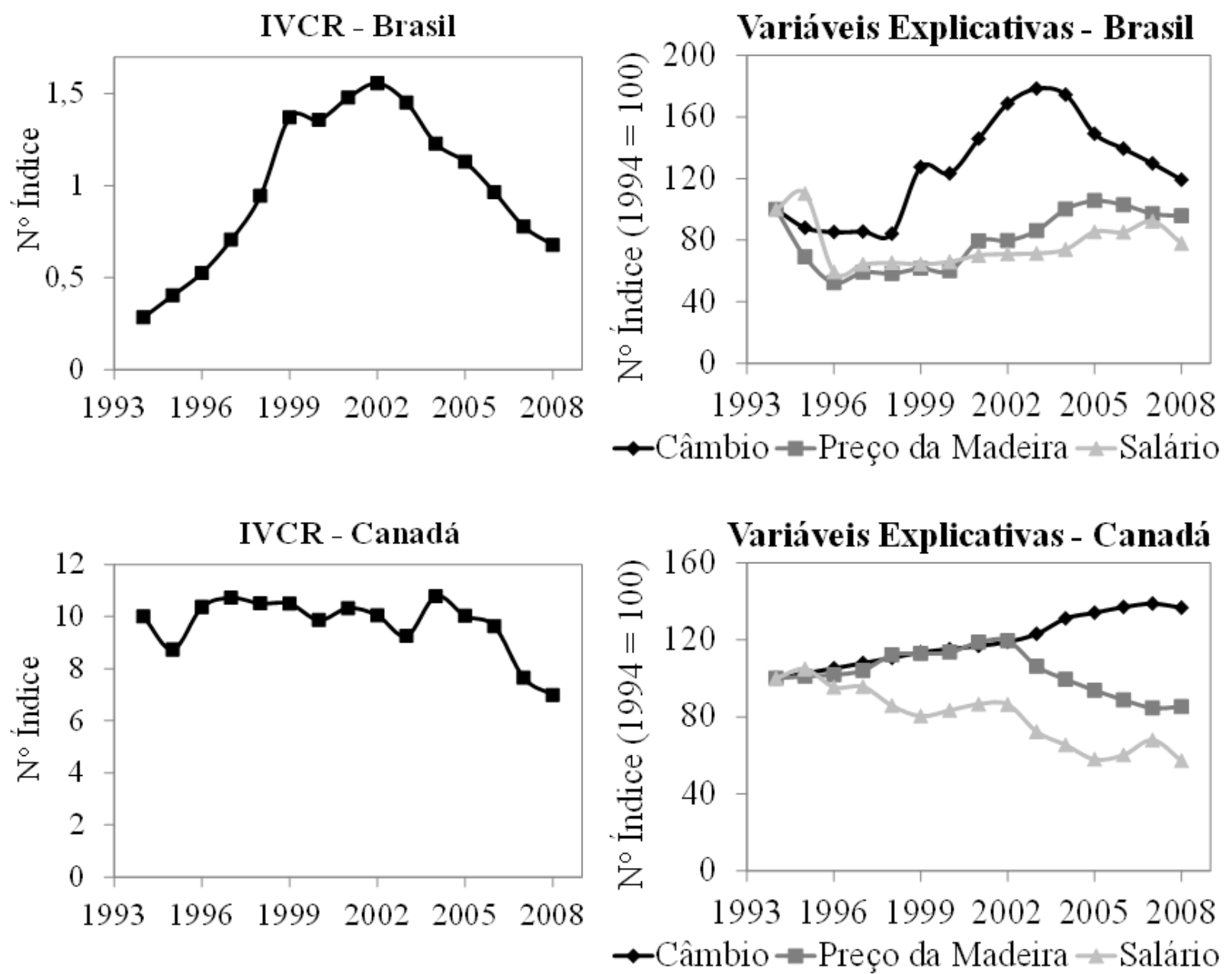

FIGURA 2: Evolução do IVCR, câmbio, custo com matéria-prima e mão de obra para o segmento de madeira serrada do Brasil e Canadá (Fonte: IPEA (2010), IBGE (2010), BC (2010) e CIS (2010)).

FIGURE 2: Evolution of IVCR, foreign exchange, cost of raw materials and manpower for the softwood lumber segment from Brazil and Canada. 
O aumento do preço da madeira a partir de 1999 foi altamente influenciado pelo câmbio favorável e crescimento das exportações. Com a valorização do real a partir de 2003 e dificuldade de atender à demanda externa pelas empresas, o mercado interno foi uma das variáveis que contribuiu para manutenção do preço da madeira em um patamar ainda elevado, lembrando que o PIB do Brasil saiu de um crescimento médio de $1,9 \%$ entre 1999 e 2003 para $4,8 \%$ entre 2004 e 2008 (IPEA, 2010).

Segundo Almeida et al. (2009b), embora o aumento do preço da madeira em tora, entre 1999 e 2005, no Brasil tenha sido decorrente de uma pressão de demanda, principalmente pelo crescimento das exportações da indústria madeireira alavancadas por um câmbio favorável, o segmento de madeira serrada não foi o principal responsável pela pressão no preço da madeira. O principal responsável por essa pressão foi o segmento de compensados, o qual, diferentemente do segmento de serrados, conseguiu ancorar quase toda a sua produção no mercado externo e sofreu menos com o aumento de preço da matéria-prima madeira nesse período.

Conforme a Figura 2, a situação canadense entre 1994 e 2008 foi muito mais estável, exceto pelos dois últimos anos da análise, devido, principalmente, aos reflexos da crise na construção civil nos EUA em sua economia. Talvez a maior vantagem competitiva das empresas no Canadá seja proveniente do maior porte das suas empresas comparativamente ao Brasil e, consequentemente, devido a altos ganhos em escala. A redução da demanda do seu principal mercado, os EUA, certamente, afetaram as vantagens decorrentes de ganhos em escala, de suas empresas.

Em um primeiro momento (1994 até 2004), a estabilidade da competitividade canadense ocorreu por meio do aumento dos salários que foram compensados por uma redução no preço da madeira e uma desvalorização cambial. A partir de 2006, a consolidação de uma tendência de valorização cambial, que se arrastava desde 2002 e foi fortemente influenciada pela crise nos EUA, reduziu drasticamente as vantagens comparativas canadenses nos dois últimos anos da análise (Figura 2).

Ao contrário do Brasil, o preço da madeira no Canadá vem apresentando uma tendência de queda, contribuindo para a competitividade do seu segmento madeireiro. Embora a produtividade das florestas no Canadá seja bem inferior à do Brasil, o país não apresenta problema de escassez de madeira. O Canadá possui metade do seu território cober- to por florestas (417.6 milhões de hectares), sendo 235 milhões de hectares considerados florestas comerciais. Considerando que apenas $0,4 \%$ das florestas comerciais canadenses são colhidas por ano e que mais da metade da área colhida é naturalmente regenerada, parece improvável um problema de falta de madeira no Canadá (REMADE, 2002).

Além da fartura de recursos florestais, ressalta-se que a grande maioria das florestas do Canadá encontra-se sob domínio do Estado, o qual é frequentemente acusado de fazer dumping da madeira, ou seja, incentivar a colheita da madeira (oferta) a uma taxa inferior à remuneração de livre mercado, levando a um preço da madeira considerado injusto, favorecendo as empresas de desdobramento locais (USDC, 2009; YIN e BAEK, 2004).

A tendência de aumento de salários para $\mathrm{o}$ segmento madeireiro no Canadá pode ser reflexo dos fenômenos oriundos da globalização. Em geral, a crescente abertura de mercado mundial tem levado a migração de indústrias de capital intensivo e de baixa intensidade tecnológica para países em desenvolvimento, buscando, entre outras vantagens, uma mão de obra mais barata, permanecendo nos países desenvolvidos, as indústrias de alta capacidade tecnológica devido às melhores condições de educação, ciência e tecnologia desses países. A indústria madeireira caracteriza-se como de baixa intensidade tecnológica e, provavelmente, a concorrência por mão de obra com segmentos mais avançados tecnologicamente no Canadá tem levado a uma pressão nos salários para essa indústria.

A transferência da base de produção florestal de países desenvolvidos para países em desenvolvimento é indicada por Tuoto (2007). Segundo o autor, os ingressos mundiais de investimentos estrangeiros diretos - IED nas atividades de silvicultura têm se concentrado em países em desenvolvimento. Por outro lado, um exemplo da mudança nos países desenvolvidos é a Nokia na Finlândia, antes uma empresa madeireira, depois empresa de papel e celulose e, atualmente, a maior fabricante de celulares do mundo (TIDD et al., 2008).

\section{CONCLUSÕES}

Além de o Canadá ser mais competitivo que o Brasil no mercado de madeira serrada de coníferas, a competitividade brasileira é altamente dependente do câmbio.

A alta produtividade das florestas no Brasil não é suficiente para tornar o país mais competiti- 
vo que o Canadá no mercado de madeira serrada de coníferas.

Embora uma estimativa do custo de mão de obra tenha que computar benefícios trabalhistas, a evolução desse custo é mais favorável à competitividade brasileira.

\section{REFERÊNCIAS BIBLIOGRÁFICAS}

ALMEIDA, A. N. et al. Influência do câmbio e preço externo nas exportações brasileiras de celulose e de madeira serrada de coníferas. Scientia Forestalis, v. 37, n. 83, p. 243-251, set. 2009a.

ALMEIDA, A. N. et al. Mercado paranaense de madeira em tora procedente de silvicultura entre 1999 e 2005. FLORESTA, v. 39, n. 4, p. 869-875, out./dez. 2009b.

BALASSA, B. Trade Liberalization and Revealed comparative advantage. The Manchester School of Economic and Social Studies, Manchester, n. 32, p. 99-123, 1965.

BC. British Columbia. Log Market Reports. Disponível em: <http:/www.for.gov.bc.ca/ hva/ logreports_coast.htm?earlier>. Acesso em: 7 nov. 2010.

CARVAlHO, K. H. A. et al. Competitiveness of brazilian wood pulp in the international market. Cerne, Lavras, v. 15, n. 4, p. 383-390, out./dez. 2009.

CIS. Canada Industry Statistic. Disponível em: $<$ http://www.ic.gc.ca/eic/site/cis-sic.nsf/eng/ Home $>$. Acesso em: 7 nov. 2010.

COUTINHO, L.; FERRAZ, J. C. Estudo da competitividade da indústria brasileira. Campinas, 1994. $472 \mathrm{p}$.

DURBIN, J.; WATSON, G. S. Testing for serial correlation in least-squares regression. Biometrika, v. 38 , p. $159-171,1951$.

FAO. Food and Agriculture Organization of the United Nations. Estatísticas Florestais. Disponível em: <http://faostat.fao.org/site/291/default.aspx>. Acesso em: 7 nov. 2010.

FIGUEIREDO, A. M.; DOS SANTOS, M. L. Evolução das vantagens comparativas do Brasil no comércio mundial de soja. Revista de Política Agrícola, v. 14, n. 1, p. 43-58, jan./mar. 2005.

GUJARATI, D. N. Econometria Básica. 3. ed., São Paulo: Makron Books, 2000. 846 p.

HAIR, Jr. J. F. et al. Análise multivariada de dados. 5. ed., Porto Alegre: Bookman, 2005. 593 p. HOLANDA, M. C. Dinâmica e determinantes da vantagem comparativa: o exemplo asiático.
Universidade Federal do Ceará, pós-graduação em Economia - CAEN, 2002 (Texto para Discussão, n. 230).

IBGE. Instituto Brasileiro de Geografia e Estatística. Anuário Estatístico Brasileiro. Disponível: $<$ http://www.ibge.gov.br/home/>. Acesso em: $07 \mathrm{de}$ nov. 2010.

IPEA. Instituto de Pesquisa Econômica Aplicado. Disponível em: <http://www.ipeadata.gov.br/ ipeaweb.dll/ipeadata?571337687>. Acesso em: 07 de nov. 2010.

KENEN, P. B. Economia Internacional: Teoria e Política. 3. ed. Rio de Janeiro: Campus, 1998. 648 p. KOUTSOYIANNIS, A. Theory of Econometrics. 2. ed. New Jersey: Barnes\&Noble Books, 1978. $683 \mathrm{p}$.

KRUGMAN, P. R.; OBSTFELD, M. Economia Internacional - Teoria e Política. 5. ed. São Paulo: Pearson Education do Brasil, 2001. 797 p.

MAIA, S. F. et al. Avaliação do PROEX para obtenção da Vantagem Comparativa Brasileira do Setor Agrícola Brasileiro: 1989-2003. 2008. SOBER. Disponível em: <www.sober.org.br/ palestra/12/03O179.pdf $>$. Acesso em: 07 de nov. 2010.

NOCE, R. et al. Competitividade do Brasil no mercado internacional de aglomerado. Revista Árvore, v. 32, n. 1, p. 113 - 118, 2008.

NOCE, R. et al. Desempenho do Brasil nas exportações de madeira serrada. Revista Árvore, v. 27, n. 5, p. 695-700, 2003.

NONNENBERG, M. J. B. Vantagens Comparativas Reveladas, Custo Relativo de Fatores e Intensidade de Recursos Naturais: Resultados para o Brasil - 1980/88. São Paulo: IPEA, 1991. (Texto para discussão, n. 214).

PINHEIRO, A. C.; HORTA, M.H. A competitividade das exportações brasileiras no período 1980/88. Pesq. Plan. Econ., v. 22, n. 3, p. 437 - 474. 1992.

PINTO, L. Agronegócio brasileiro e mercados globalizados. Boletim Pecuário. set. 2004. Disponível em: $<\mathrm{http}: / /$ www.boletimpecuario.com. br> Acesso em: 15 out. 2009.

REMADE. Revista da Madeira. n.66, ago. 2002. ROPKE, C. R. V.; PALMEIRA, E. M. Competitividade das exportações brasileiras de couro. Revista académica de economia, n. 71, p. $1-7$. Dic. 2006.

SALVATORE, D. Economia Internacional. 6. ed. Rio de Janeiro: Prentice Hall, 1998. 436 p.

TIDD, J. et al. Gestão da Inovação. 3. ed., Porto Alegre: Bookman, 2008. 600 p. 
TUOTO, M. A. M. Os investimentos estrangeiros diretos no Brasil: um estudo de caso do setor florestal. 2007. 121 f. Dissertação (Mestrado em Ciências Florestais) - Setor de Ciências Agrárias, Universidade Federal do Paraná, Curitiba, 2007.

UnCOMTRADE. United Nations Commodity Trade Statistics database. Disponível em: $<\mathrm{http} / / /$ comtrade.un.org/db/default.aspx $>$. Acesso em: 07 de nov. 2010.

USCB. United State Census Bureau. Disponível em: $<$ http://www.census.gov/>. Acesso em: $07 \mathrm{de}$ nov. 2010.

USDC. United State Departament of Commerce. Softwood lumber subsidies report to the congress.
December 2009. Disponível em: $<$ http://ia.ita.doc. gov/sla2008/reports /softwood-lumber-subsidiesreport-121809.pdf>. Acesso em: 07 de nov. 2010.

VALVERDE, S. R. et al. Desempenho das exportações brasileiras de celulose. Revista Árvore, v. 30, n. 6, p. 1017-1023, 2006.

WHITE. H. A Heteroscdasticity Consistent Covariance Matrix Estimator and a Direct Test of Heteroscedasticity. Econometrica, v. 48, p. 817 818, 1980.

YIN, R.; BAEK, J. The US-Canada softwood lumber trade dispute: what we know and what we need to know. Forest Policy and Economics, v. 6, p. 129-143. 2004. 